\title{
Environmental determination of the male morph in the ant Cardiocondyla obscurior (Hymenoptera: Formicidae)
}

\author{
YANYANG DU, AleXANDRA SCHREMPF and JÜRGEN HEINZE*
}

Biology I, University of Regensburg, Universitätsstraße 31, D-93040 Regensburg, Germany; e-mails: alexandra.schrempf@biologie.uni-regensburg.de; juergen.heinze@biologie.uni-regensburg.de

Key words. Formicidae, male dimorphism, environmental morph determination, Cardiocondyla, ergatoid males

\begin{abstract}
Cardiocondyla is one of the few ant genera in which winged dispersing males coexist with wingless fighter males, which predominantly mate inside their maternal nests. Male polymorphism is not genetically determined but induced by environmental conditions (e.g., a decrease in temperature). The factors leading to the production of winged males were studied in more detail by exposing colonies of C. obscurior to a specific set of rearing conditions. A "stressful" environmental condition (rearing temperature lowered on average by $5^{\circ} \mathrm{C}$ ) experienced for at least two days, the decrease of temperature by a minimum of $3^{\circ} \mathrm{C}$, and the addition of protein-rich food triggered the development of winged males. In contrast, a smaller decrease in temperature, starvation, encounters with workers from other species, and encounters with alien, conspecific winged males did not induce the production of winged males. Colonies differed strongly in their reaction to changing environmental conditions, which might indicate a difference in their threshold sensitivity. The results are discussed and compared with data from other dimorphic insect species.
\end{abstract}

\section{INTRODUCTION}

Many species of the ant genus Cardiocondyla are characterised by an extraordinary male dimorphism, with typical winged ant males, which disperse from the nest to mate with queens from other colonies, and worker-like, wingless males. Such "ergatoid males" never leave their natal nests but fight among themselves to gain access to virgin queens produced by their maternal colonies (Kinomura \& Yamauchi, 1987; Stuart et al., 1987; Yamauchi \& Kawase, 1992; Heinze et al., 1993, 1998; Heinze \& Trenkle, 1997; Heinze, 1999).

Previous studies on the proximate mechanisms underlying male dimorphism in Cardiocondyla revealed that the male morph is indirectly determined by changes in environmental conditions via changes in the behaviour of workers towards male larvae. Male second instar larvae that experience a change in worker attention under stressful environmental conditions, e.g., a sudden decrease of $5^{\circ} \mathrm{C}$ in rearing temperature (Cremer \& Heinze, 2003), develop into winged males (Schrempf \& Heinze, 2006), and those that do not experience such a change develop into ergatoid males. In addition, the study by Cremer \& Heinze (2003) indicates that the expression of the male morph is independent of the morph of the grandfather, i.e., it does not have a heritable basis. As in other cases (Nijhout, 1994; Liu et al., 2005), the changes in the environment are transcribed into a change in juvenile hormone titre. Treatment of first and second instar larvae of $C$. obscurior with methoprene (a $\mathrm{JH}$ analogue) led to the production of both winged males and female sexuals (Schrempf \& Heinze, 2006).

\footnotetext{
* Corresponding author.
}

Previous studies describe the influence of temperature changes on morph development, but the minimum degree of stress needed to elicit the production of winged males, the duration of the response to stress and the effect of potential stressors other than temperature have as yet not been investigated.

In this study, the rapidity and duration of the stress response, and the minimum temperature change that causes a response were determined. Furthermore, it was examined whether extra high quality (protein-rich) food, starvation, increased predation risk, or the occurrence of alien, conspecific winged males triggers the formation of the winged morph.

\section{MATERIAL AND METHODS}

Cardiocondyla obscurior (Wheeler, 1929) colonies were collected from nests in rolled lemon leaves in a lemon plantation at CEPLAC, Itabuna, Brazil in March 1998 and Sept. 2000. They were placed into plaster nests $(10 \mathrm{~cm} \times 10 \mathrm{~cm} \times 3 \mathrm{~cm})$ in the laboratory and kept in incubators at $30^{\circ} / 25^{\circ} \mathrm{C}, 12 \mathrm{~L}: 12 \mathrm{D}$ cycles and a constant humidity of approximately $98 \%$. They were fed three times per week with honey and pieces of dead insects. Before the start of the experiments, 84 colonies were observed for three to six weeks to ensure that they only produced ergatoid males. Four colonies, which did not produce males during this period, were excluded from further experiments.

To determine how long colonies need to be exposed to "temperature stress" to elicit the production of winged males, six to nine colonies were subjected to room temperature (on average $5^{\circ} \mathrm{C}$ lower than standard rearing temperature, appr. $24^{\circ} \mathrm{C} /$ day and $21^{\circ} \mathrm{C} / \mathrm{night}$; room temperature was measured regularly during the day; data for temperatures during the night were gained from climatic technicians of the university, and - in addition - measured irregularly) for 20, 10, 5, 3, 2 and 1 day(s) each. After being "stressed," the colonies were transferred back 
TABLE 1. Duration of "temperature stress", the number of colonies tested, and observation time in the experiments on male morph determination in the ant Cardiocondyla obscurior $(\mathrm{NC}=$ negative control under standard rearing temperature; PC $=$ positive control under room temperature).

\begin{tabular}{lcccccccc}
\hline & \multirow{2}{*}{ NC } & & & \multicolumn{6}{c}{ "Stress" (days) } \\
\cline { 3 - 9 } & & & 20 & 10 & 5 & 3 & 2 & 1 \\
\hline Number of colonies & 8 & 6 & 6 & 9 & 6 & 6 & 6 & 7 \\
\hline Observation time (weeks) & 19 & 17 & 10 & 10 & 5 & 5 & 4 & 4 \\
\hline
\end{tabular}

into their original climatic chamber and reared under standard conditions for an additional three to six weeks. Six colonies kept for 17 weeks at room temperature served as positive controls, eight colonies kept under standard conditions in an incubator for 19 weeks served as negative controls (see Table 1). All colonies were observed three times per week. The start of and duration of winged male production were recorded. If rearing temperatures are decreased by $8^{\circ} \mathrm{C}$ or more, the production of brood decreases and the development of winged males ceases, presumably because of the low foraging activity of the workers of this tropical ant at low temperatures (E. Huber \& A. Schrempf, unpubl.).

To determine the minimum temperature decrease needed to elicit winged male production, five "unstressed" colonies each were exposed to temperatures that were $2^{\circ} \mathrm{C}$ and $3^{\circ} \mathrm{C}$ lower than standard rearing temperatures, i.e., $28^{\circ} / 23^{\circ} \mathrm{C}$ and $27^{\circ} / 22^{\circ} \mathrm{C}$ at $12 \mathrm{~L}: 12 \mathrm{D}$ cycles. All other conditions remained unchanged. The two groups were observed for 19 and 5 weeks, respectively.

Winged males are significantly larger than ergatoid males and presumably require additional or other nutrition during their development. We therefore investigated the influence of diet quality and / or quantity on the occurrence of winged males. In a first experiment, we provided additional protein (two crushed Cardiocondyla pupae each) to six unstressed colonies three to five times per week over a period of five weeks. According to previous observations, dead pupae are carried into the nest and readily eaten. Colony productivity was monitored over a total of 8 weeks. In a second experiment, two small "unstressed" colonies were starved by only feeding them honey and water once or twice per week for 6 weeks.

To determine whether stress, through predation, induces the production of winged males, we introduced single workers of the ant Lasius emarginatus, as territory intruders or resource competitors, into the nest boxes of "unstressed" C. obscurior colonies. L. emarginatus colonies were fed only once per week and hungry $L$. emarginatus quickly engaged in fighting with $C$. obscurior, killed adults, and fed on eggs and larvae. One $L$. emarginatus worker was placed into each of five "unstressed" C. obscurior colonies twice per day for three weeks. Colony productivity was monitored for six weeks.

Finally, we examined whether the presence of alien winged males leads to the production of new winged males in "unstressed" colonies. A single alien winged male was placed into each of five "unstressed" colonies (and left there) three times per week. The colonies were manipulated for four weeks and observed for six weeks.

All data were analyzed with the software packages Excel and Statistica. A Spearman Rank correlation was used to check for a relation between the duration of stress and the number of reacting colonies. After confirming that data were normally distributed (Kolmogorov-Smirnov-test, $\mathrm{p}>0.05$ ), ANOVA or ANCOVA were carried out to detect differences between the respective treatments.

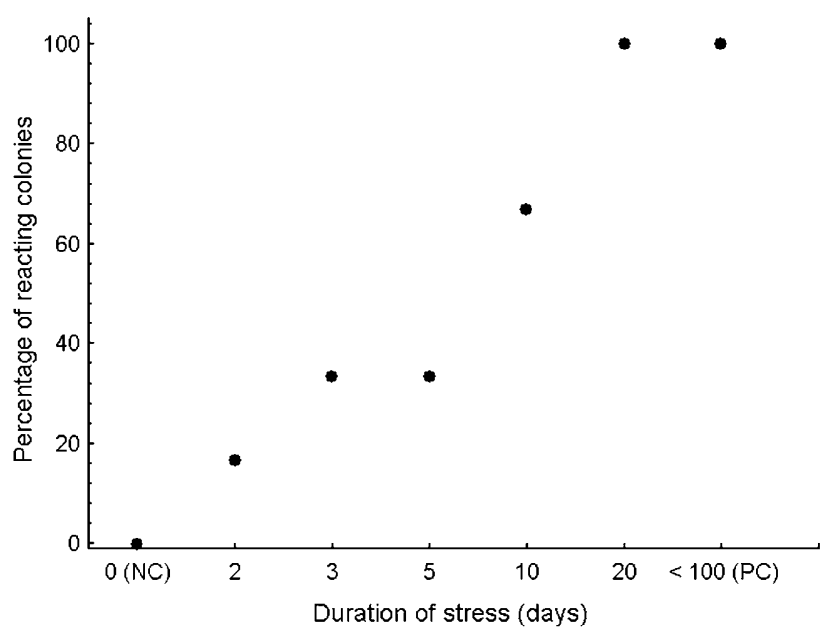

Fig. 1. Correlation between the percentage of colonies that reacted by producing winged males within five weeks after being "stressed" by a $5^{\circ} \mathrm{C}$ decrease in rearing temperature and the duration of exposure to "stress" (0 (neg. control), 1, 2, 3, 5, 10,20 or $>100$ days (positive control), respectively: SpearmanRank-correlation: $\left.\mathrm{N}=8, \mathrm{r}_{\mathrm{S}}=0.98, \mathrm{p}<0.0001\right)$.

\section{RESULTS}

The response of colonies to stress increased with the duration of stress, e.g., exposing colonies to a rearing temperature lowered by on average $5^{\circ} \mathrm{C}\left(24^{\circ} \mathrm{C} / 21^{\circ} \mathrm{C}\right.$ day/night) for only one day did not result in the production of winged males, whereas all colonies produced winged males after experiencing stress for 20 days (Fig. 1). All positive controls, which were exposed to room temperature throughout the whole experiment, produced winged males, while the colonies of the negative control in the incubators did not produce winged males during the first five weeks of the experiment. In four of these negative control colonies a few winged males developed spontaneously late in the experiment although there was no change in environmental conditions.

Colonies very quickly responded to "temperature stress": in one colony, winged male pupae were first found 8 days after the change in rearing conditions. Therefore, it appears that workers changed their nursing behaviour immediately after experiencing stressful conditions. On average, first winged male pupae were present in colonies within two weeks of the decrease in temperature (Fig. 2). At the latest, colonies contained winged males after 3 weeks. In contrast, the negative control produced a few winged males significantly later (at the earliest after 35 days, on average after 46 days).

Most of the positive control colonies continued to produce winged males throughout the duration of exposure to lower temperature, however, in three colonies winged male production ceased temporarily (for several days up to several weeks). In contrast, colonies, which were returned to standard rearing conditions after "stress," quickly stopped producing winged males and produced exclusively ergatoid males (Fig. 3).

While a long-term temperature drop of approximately $5^{\circ} \mathrm{C}$ led to the production of winged males in all colonies 


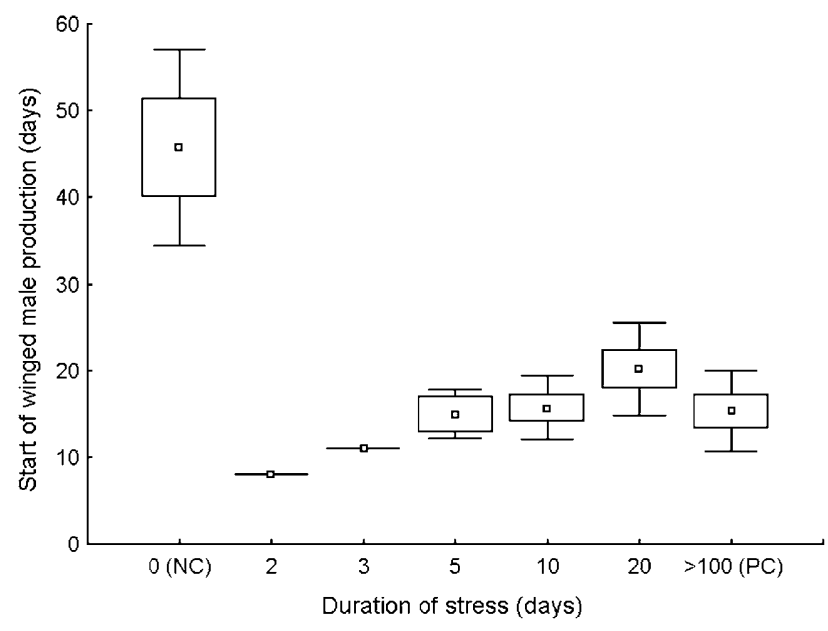

Fig. 2. Mean ( \pm SE and SD) time in days to the start of winged male production in colonies of the ant Cardiocondyla obscurior after experiencing a temperature decrease for 2, 3, 5, 10 or 20 days, as well as in positive and negative control colonies (PC and $\mathrm{NC}$ ). Colonies on average produced winged males after 14 days, independent of the duration of stress. Some negative control colonies produced a few winged males, but significantly later than all other groups. Colony size, i.e. worker number, did not influence the time of the start of winged male production (ANCOVA with worker number as a cofactor: $\mathrm{F}=$ $2.50, \mathrm{P}>0.01$; start of winged male production: $\mathrm{F}=16.74, \mathrm{P}<<$ 0.05 ; post hoc LSD tests: negative control vs. all combinations, $\mathrm{P}<<0.05$; all other combinations: $\mathrm{P}>0.05$ ).

tested, a decrease of $3^{\circ} \mathrm{C}$ elicited winged male production in only two of five colonies, and not a single colony reacted to a drop of $2^{\circ} \mathrm{C}$.

Adding additional proteinaceous food in the form of crushed Cardiocondyla pupae stimulated the production of winged males in 2 of 6 colonies. In contrast to an earlier, casual observation (Cremer \& Heinze, 2003), starvation did not lead to winged male production. Instead, the number of brood and adults in starved colonies decreased rapidly and the two colonies died.

The introduction of Lasius workers or alien winged males did not result in the production of winged males. Thus, colonies seem not to be "stressed" by alien intruders or stimulated to produce winged males even though other colonies in the population did produce such males.

\section{DISCUSSION}

The production of winged males in the ant Cardiocondyla obscurior was elicited in the laboratory by a sudden decrease in temperature of at least $3^{\circ} \mathrm{C}$, a temperature drop of $5^{\circ} \mathrm{C}$ for more than two days, and by supplying crushed pupae as food. Other manipulations did not result in the development of the winged morph. Colonies appeared to be differently sensitive to environmental changes and not all colonies reacted to the more subtle or short-lasting periods of stress. In addition, some, but not all colonies spontaneously produced a few winged males even under the constant conditions in an incubator, suggesting that they had either responded to other influences

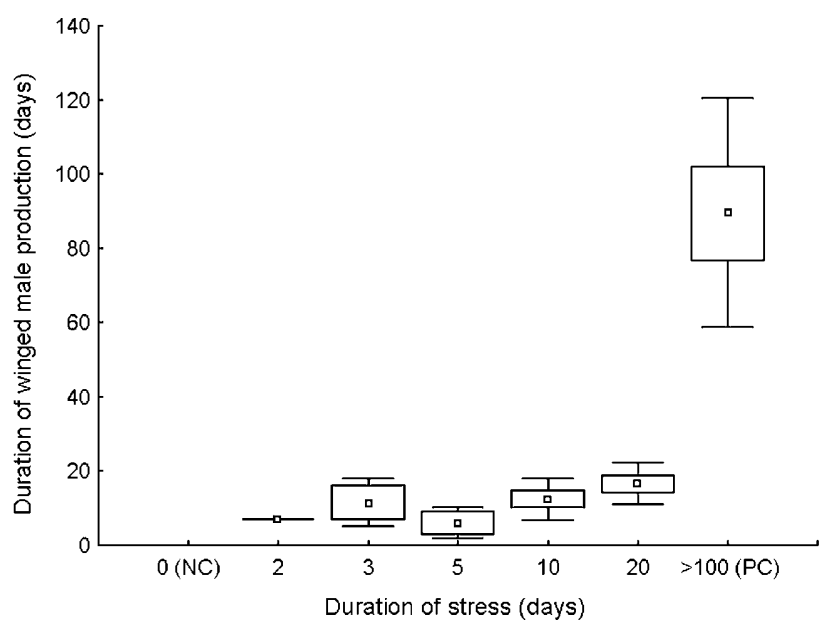

Fig. 3. Mean ( \pm SE and SD) duration of winged male production in colonies of the ant Cardiocondyla obscurior stressed for $2,3,5,10$ or 20 days, as well as in positive and negative control colonies (PC and NC). The duration of stress did not affect the duration of winged male production in colonies except for the positive control: stressed colonies stopped producing winged males shortly after being returned to a standard rearing temperature. In contrast, the positive controls produced winged males for significantly longer (ANOVA: $\mathrm{F}=11.43, \mathrm{P}<<0.01$; post hoc LSD tests: positive control vs. all others: $\mathrm{P}<<0.05$; all other combinations: $\mathrm{P}>0.05$ ).

or that these colonies were extremely sensitive and reacted to the regular checks at room temperature. Neither the introduction of territorial intruders nor that of alien winged males led to the production of winged males, suggesting that workers were not stressed by such occasional, short periods of disturbance.

At present, it is unknown why colonies differ so strongly in their reaction to environmental changes. Our results might indicate that the switch point, which controls the production of winged males, varies among colonies. Variation in the thresholds for the expression of alternative morphs has previously been reported for dung beetles, Onthophagus taurus (Moczek, 2003; Moczek \& Nijhout, 2003) and mites (Tomkins \& Brown, 2004), and appears to facilitate an adaptive reaction to environmental change (Emlen, 1994, 1996; Roff, 1994).

The existence of species of Cardiocondyla lacking winged males and of species with wingless and "intermorphic" males (Yamauchi et al., 2005) suggests genetic variation in the response threshold. Furthermore, cross-breeding within the related socially parasitic genus, Myrmoxenus, likewise points to the heritability of the switch point in environmental caste differentiation. Some Myrmoxenus species are active slave-makers and produce large numbers of workers, whereas other species are workerless, "degenerate" slave-makers, whose queens only produce sexual offspring. Hybrids between species showed intermediate caste ratios (Jessen \& Klinkicht, 1990; Buschinger, 2001). However, the Cardiocondyla colonies we used were presumably highly inbred and therefore strong intra-population variation in a putative genetic threshold is unlikely. Further research is needed 
to determine whether sensitivity varies consistently among colonies or whether the production of winged males is affected by epigenetic, idiosyncratic properties of individual colonies.

The production of winged males by colonies to which crushed $C$. obscurior were provided as food might be a direct response to a protein-rich diet. Winged males are considerably larger and heavier than ergatoid males. Nutrition often plays an important role in morph and caste determination. For example, morphogenesis in Trichogramma semblidis and Melittobia chalybii is affected by the quality rather than the quantity of food (Salt, 1937; Schmieder, 1933). A protein-rich diet might elevate the JH-level in Cardiocondyla larvae, as, e.g., in honey bee queens (Wirtz, 1973). Alternatively, providing crushed pupae might have elicited an alarm response in the workers, similar to that induced by a reduction in colony size or temperature decline (Cremer \& Heinze, 2003). Alarm pheromones released by attacked pea aphids induce other individuals to give birth to winged offspring (Kunert et al., 2005), and ant pheromones leaking from the glands of crushed pupae might have a similar effect. In the future, other experiments, e.g., feeding the colonies with other protein-rich food, might reveal, which of these two explanations is correct.

In our experiment, colonies showed a quick reaction to a change in environmental conditions, which suggests a high sensitivity and a swift reaction of workers to variation in critical environmental conditions. An obvious question arising from this is whether such sudden temperature changes are a common component of the natural environment of this species. Climate data show that dayto-day changes in average temperature of more $2^{\circ} \mathrm{C}$ are rare in our study population in Brazil (J.H.C. Delabie, pers. comm.), which explains why no winged males were found in natural colonies over a period of 13 months (Heinze \& Delabie, 2005). However, it must be noted that C. obscurior is not native to Brazil, but presumably was introduced from somewhere in the paleotropics. Little is known of the climatic conditions in its native range, but winged males have been collected in Southeast Asia (K. Yamauchi, pers. comm.).

ACKNOWLEDGEMENTS. Our research was supported by DFG (He 1623/22).

\section{REFERENCES}

Buschinger A. 2001: Multiple Hybridisierung von Arten der Ameisen-Gattung Epimyrma (Hymenoptera: Formicidae), und Beobachtungen zur Ausbeutung der Wirtsarten durch die Parasiten. Myrmec. Nachr. 4: 25-35.

Cremer S. \& Heinze J. 2003: Stress grows wings. Environmental induction of winged dispersal males in Cardiocondyla ants. Curr. Biol. 13: 219-223.

EMLEN D.J. 1994: Environmental control of horn length dimorphism in the beetle Onthophagus acuminatus (Coleoptera: Scarabaeidae). Proc. R. Soc. Lond. (B): 256: 131-136.

EMLEN D.J. 1996: Artificial selection on horn length-body size allometry in the horned beetle Onthophagus acuminatus (Coleoptera: Scarabaeidae). Evolution 50: 1219-1229.
Heinze J. 1999: Male polymorphism in the ant Cardiocondyla minutior (Hymenoptera: Formicidae). Entomol. Gen. 23: 251-258.

Heinze J. \& Delabie J.H.C. 2005: Population structure of the male-polymorphic ant Cardiocondyla obscurior. Stud. Neotrop. Fauna Envir. 40: 187-190.

Heinze J. \& Trenkle S. 1997: Male polymorphism and gynandromorphs in the ant Cardiocondyla emeryi. Naturwissenschaften 84: 129-131.

Heinze J., Kühnholz S., Schilder K. \& Hölldobler B. 1993: Behavior of ergatoid males in the ant, Cardiocondyla nuda. Insect. Soc. 40: 273-282.

Heinze J., Hölldobler B. \& Yamauchi K. 1998: Male competition in Cardiocondyla ants. Behav. Ecol. Sociobiol. 42: 239-246.

Jessen K. \& KLinkicht M. 1990: Hybridisation in the social parasitic ant genus Epimyrma (Hymenoptera, Formicidae). Insect. Soc. 37: 273-293.

Kinomura K. \& Yamauchi K. 1987: Fighting and mating behaviors of dimorphic males in the ant Cardiocondyla wroughtonii. J. Ethol. 5: 75-81.

Kunert G., Otto S., Röse U.S.R., Gershenzon J. \& Weisser W.W. 2005: Alarm pheromone mediates production of dispersal morphs in aphids. Ecol. Lett. 8: 596-603.

Liu Y., Henderson G. \& LaineEt R.A. 2005: Effects of temperature and nutrition on juvenile hormone titers of Coptotermes formosanus (Isoptera: Rhinotermitidae). Ann. Entomol. Soc. Am. 98: 732-737.

MoczeK A.P. 2003: The behavioral ecology of threshold evolution in a polyphenic beetle. Behav. Ecol. 14: 841-854.

Moczeк A.P. \& Nijhout H.F. 2003: Rapid evolution of a polyphenic threshold. Evol. Dev. 5: 259-268.

Nishout H.F. 1994: Insect Hormones. Princeton University Press, Princeton, NJ, $280 \mathrm{pp}$.

RofF D. A. 1994: Habitat persistence and the evolution of wing dimorphism in insects. Am. Nat. 144: 772-798.

Salt G. 1937: The egg parasite of Sialis lutaria: a study of the influence of the host upon a dimorphic parasite. Parasitology 29: 539-553.

SCHMIEDER R.G. 1933: The polymorphic forms of Melittobia chalybii Ashmead and the determining factors involved in their production (Hymenoptera: Chalcidoidea, Eulophidae). Biol. Bull. 65: 338-354.

SchrempF A. \& Heinze J. 2006: Proximate mechanisms of male morph determination in the ant Cardiocondyla obscurior. Evol. Dev. 8: 266.

Stuart R.J., Francoeur A. \& Loiselle R. 1987: Lethal fighting among dimorphic males of the ant, Cardiocondyla wroughtonii. Naturwissenschaften 74: 548-549.

Tomkins J.L. \& Brown G.S. 2004: Population density drives the local evolution of a threshold dimorphism. Nature 431: 1099-1108.

WIRTZ P. 1973: Differentiation in the honeybee larva. Med. Landb-hoogesch. Wageningen 73: 5.

Yamauchi K. \& Kawase N. 1992: Pheromonal manipulation of workers by a fighting male to kill his rival males in the ant Cardiocondyla wroughtonii. Naturwissenschaften 79: 274-276.

Yamauchi K., Asano Y., Lautenschläger B., Trindl A. \& HeInZE J. 2005: A new type of male dimorphism with ergatoid and short-winged males in Cardiocondyla cf. kagutsuchi. Insect. Soc. 52: 274-281.

Received August 21, 2006; revised and accepted November 16, 2006 